\title{
Research Paper: Relationship Between Performance Evaluation and Therapists' Job Motivation of Rehabilitation Centers and Public Hospitals of Tehran Based on Herzbergs' Two-Factor Model

\author{
Elahe Abolhoseini ${ }^{1}$, ${ }^{\text {Hosein }}$ Mobaraki ${ }^{1}$, Mohammad Kamali ${ }^{1}$, Nasrin Shaarbafchi-Zade ${ }^{1}$
}

1. Department of Rehabilitation Management, School of Rehabilitation Sciences, Iran University of Medical Sciences, Tehran, Iran.

\begin{tabular}{|c|c|}
\hline $\begin{array}{l}\text { Use your device to scan } \\
\text { and read the article online }\end{array}$ & Crtation: Abolhoseini E, Mobaraki H, Kamali M, Shaarbafchi-Zade N. [Relationship Between Performance Evaluation and \\
\hline 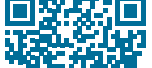 & $\begin{array}{l}\text { Therapists' Job Motivation of Rehabilitation Centers and Public Hospitals of Tehran Based on Herzbergs' Two-Factor Model } \\
\text { (Persian)]. Archives of Rehabilitation. 2018; 18(4):316-327. https://doi.org/10.21859/JREHAB.18.4.6 }\end{array}$ \\
\hline 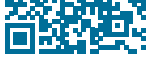 & dol": https://doi.org/10.21859/JREHAB.18.4.6 \\
\hline
\end{tabular}

Received: 19 Jun. 2017 Accepted: 11 Sep. 2017

Keywords: Performance evaluation, Job motivation, Rehabilitation therapists, Herzberg's two-factors model

\begin{abstract}
Objective This study aims at examining the relationship between performance evaluation and therapist's job motivation based on Herzberg's two-factor model.

Materials \& Methods This study was a cross-sectional study conducted in 1394 that was performed on 80 rehabilitation therapists working in rehabilitation centers and government hospitals in Tehran. Sampling was done by cluster sampling method. The data collection tool included two standard questionnaires that employed performance evaluation and Herzberg's 40 material job motivation. Before any analysis, the variables were tested for normality with the Kolmogorov-Smirnov test. Based on the normality of variables, data were analyzed using descriptive statistics, independent t-test and Pearson correlation by SPSS software. Results The results showed that from therapists' point of view, $90 \%$ of them stated that performance of the organization was essential and $88.8 \%$ said that performance evaluation was effective on job motivation. However, $55.7 \%$ of therapists, did not like the current performance evaluation. In this study, there was no significant relationship between therapist's job motivation and performance evaluation $(P=0.47)$. From therapists' point of view, the motivational factors (internal) had greater importance than hygiene factors (external). Accordingly, this study is in line with Herzberg's research. Job quality, responsibilities of job, job level, job security and salary had the highest role in motivation and effective performance. Based on the results of the statistical tests, no significant correlation was found between demographic variables such as gender, education level, marital status, place of work and rehabilitation therapists' degree of performance evaluation. A significant correlation was observed between therapists' work experience variable with performance evaluation and Herzberg's motivation theory $(P=0.04)$. According to the results, the relationship between employment type of rehabilitation therapists and performance evaluation was significant $(P<0.006)$. There was a significant relationship between age and job motivation theory of Herzberg in the therapists community $(\mathrm{P}=0.02)$.

Conclusion It seems that with regard to the difficulty of rehabilitation therapists' job, it is essential that necessary training for supervisors and managers and directors are organized in order to achieve organizational objectives by taking advantage of the performance standards and evaluation criteria. This will lead to an increase in the rehabilitation therapists' job motivation and provide for them work progress and greater encouragement.
\end{abstract}

\section{* Corresponding Author: \\ Hosein Mobaraki, PhD}

Address: Department of Rehabilitation Management, School of Rehabilitation Sciences, Iran University of Medical Sciences, Tehran, Iran. Tel: +98 (917) 1505249

E-Mail: hmobaraki43@yahoo.com 


\title{
بررسى ارتباط ارزشيابى عملكرد با انكيزش شغلى درمانگَران مراكز توانبخشى و بيمارستانهاى

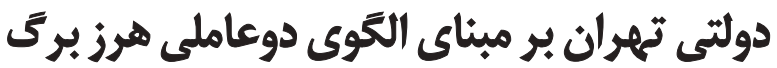

\author{
الهه ابوالحسينى'، "خسين مباركى'، محمد كمالى'، نسرين شعربافجىزاده' \\ ا - كروه مديريت توانبشى، دانشكده علوم توانبخى، دانشكاه علوم يزشكى ايران، تهران، ايران.
}

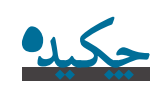

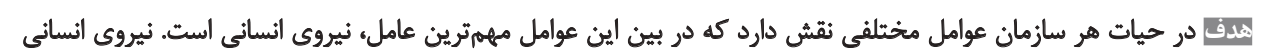

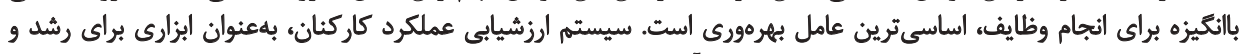

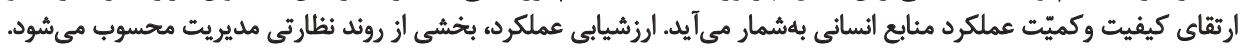

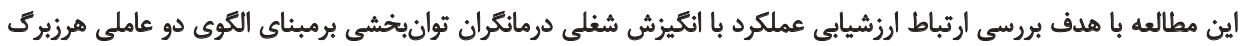
انجام شاند.

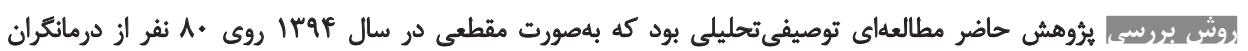

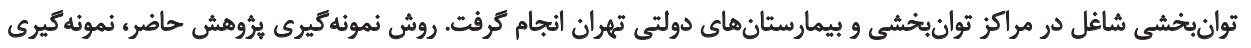

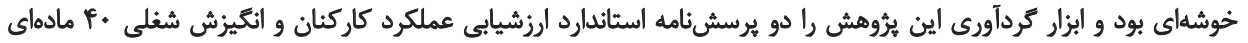

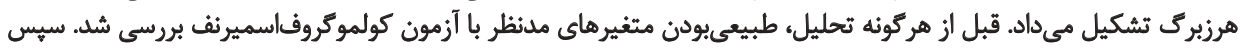

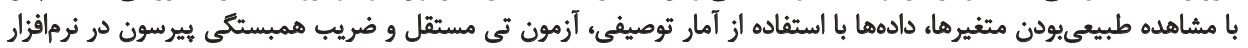
SPSS تجزيهوتحليل شد.

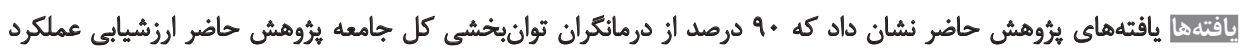

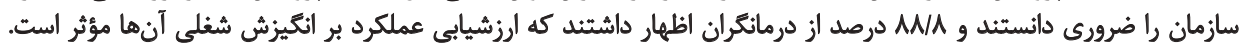

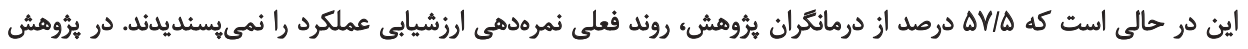

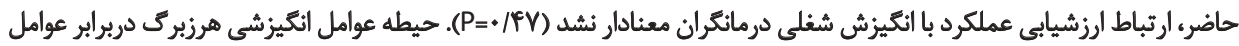

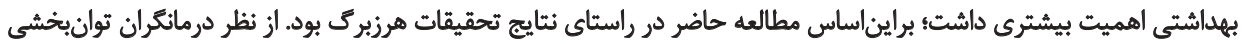

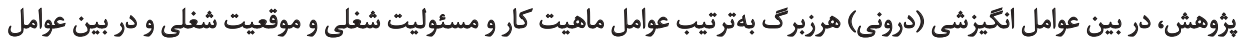

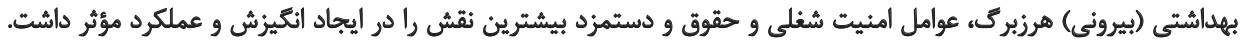

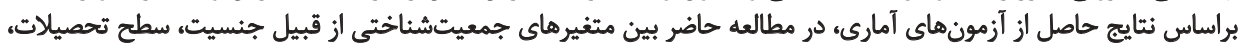

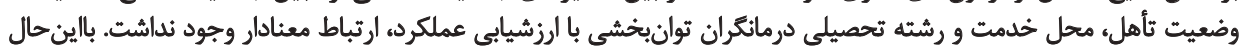

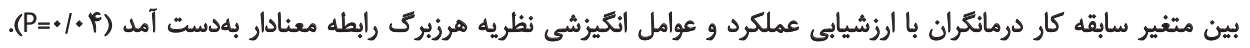

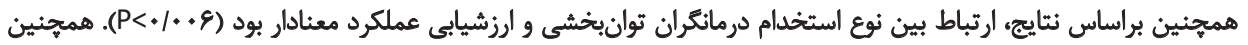

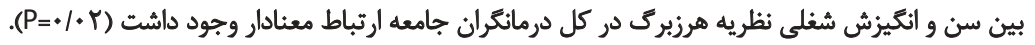

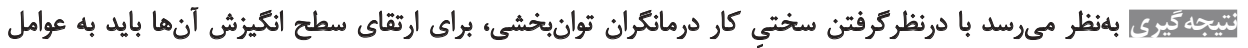

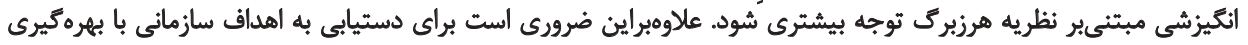

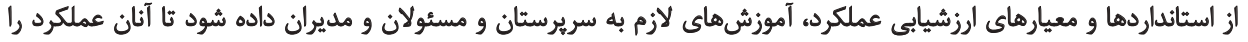

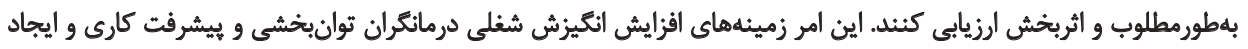

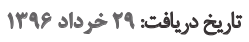

تاريخ بذيرش: +r شهيريور 
وجود دارد كه بايد مديران و سياست كذاران آن را درنظركيرند. از مقدمه

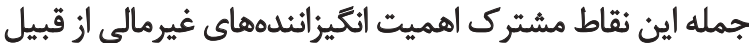

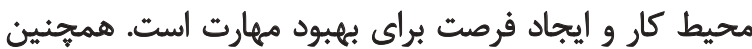

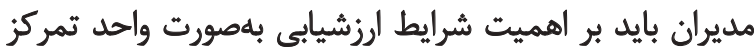

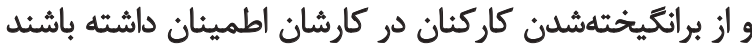

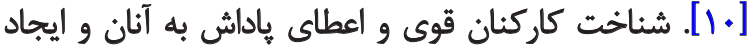

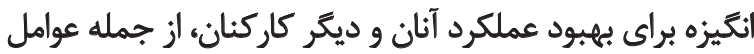

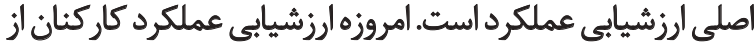

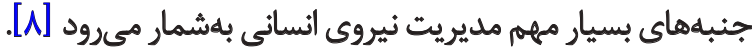

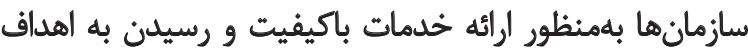

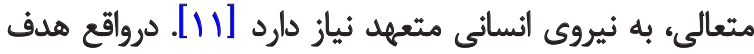

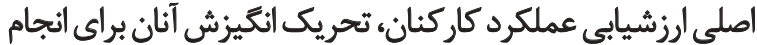

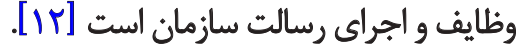

طرح ارزشيابى كاركنان در نظام ادارى ايران موضوع بسيار

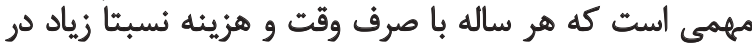

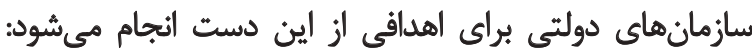

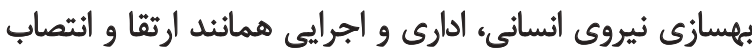

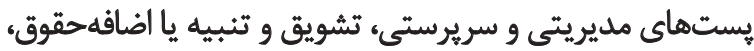
بازخورد عملكرد كاركنان و تشخيص نيازهاي آموزشى آنان [A] ارزشيابي بلمعنى علمى و دقيق آن، دانش جوانى است كه

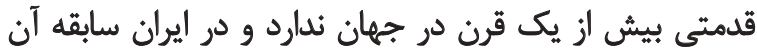

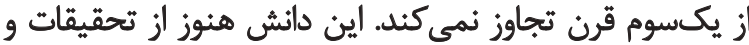

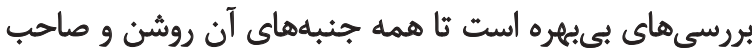

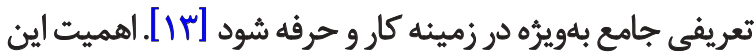

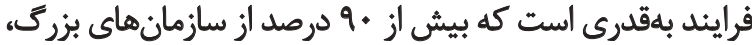

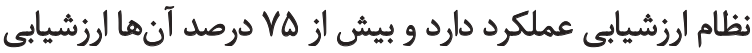

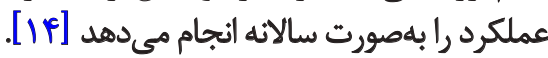
ارزشيابي باكيفيتى كه درحال حاضر در كشور ما انجام مي شوده،

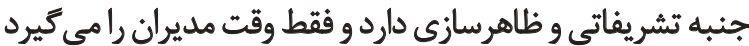

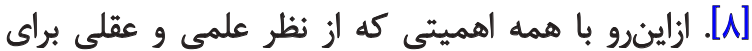

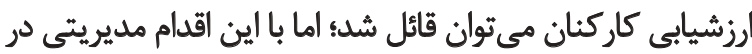

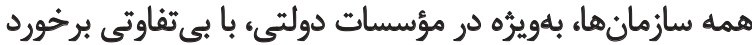

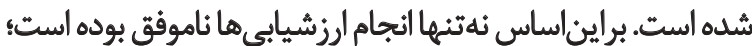

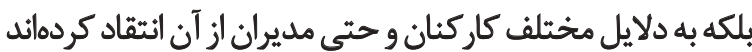

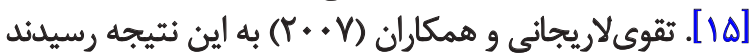

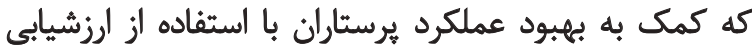

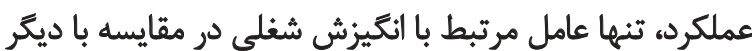

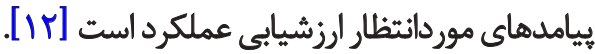

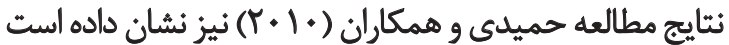

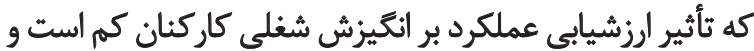

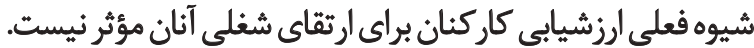

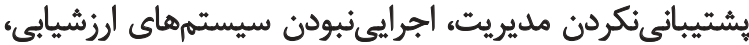

در حيات هر سازمان عوامل مختلفى نقش دارند. مهمثرين اين عوامل عبارت است ازئ نيروى انسانى و ماشين آلآلات و سرمايه.

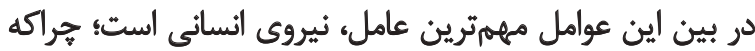

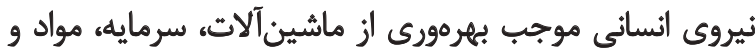

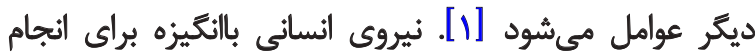

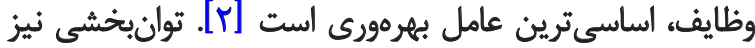

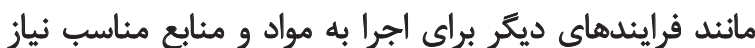

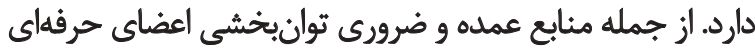

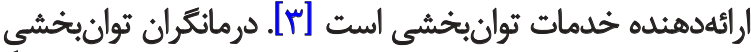

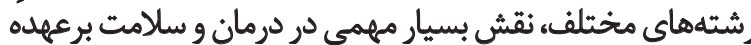

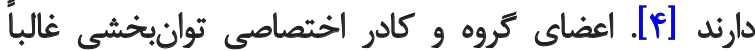

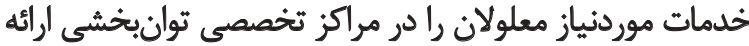

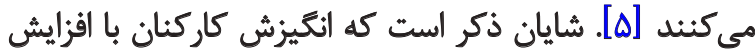

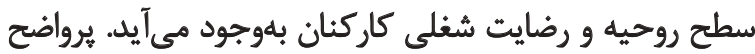

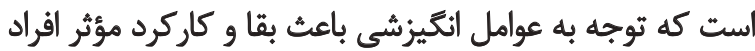

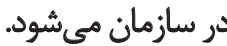
در اين راستانظريه دوعاملى لانغيزشىبهداشتى" هرزبرك، يكى

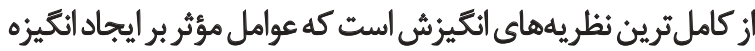

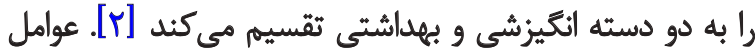

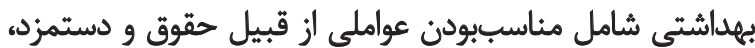

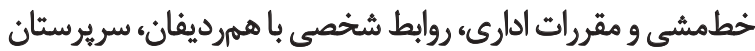
و زيردستان، امنيت شغلى، شرايط محيط كار و و سريرستي

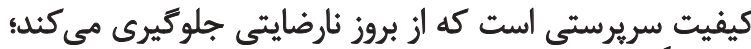

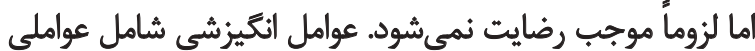

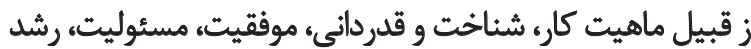

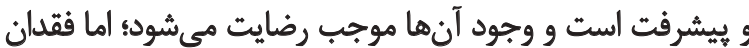

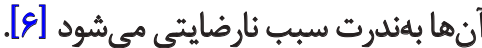

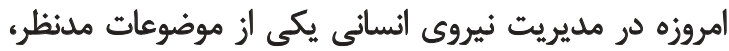

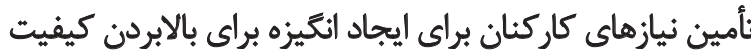

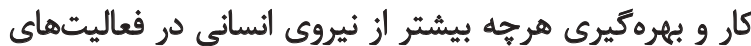

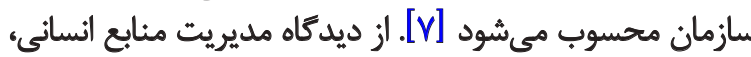

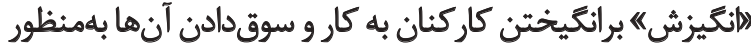

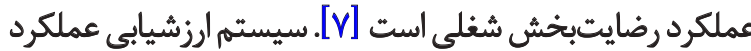

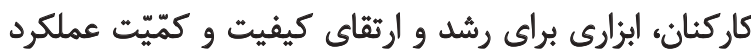

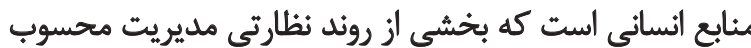

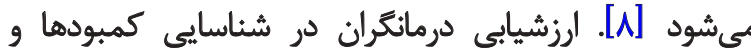

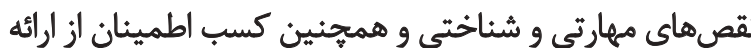

مطلوب مراقبتها اهميت فراوان دارد [9]

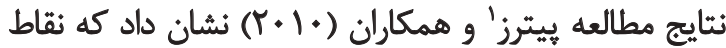

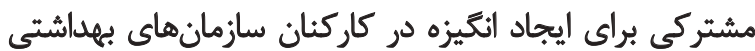


از بين آنها انتخاب شد. در مراجعه حضورى به بيمارستانها و وران

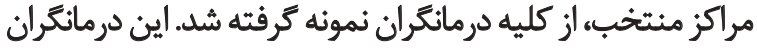

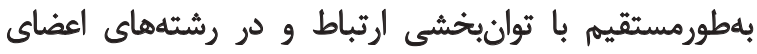

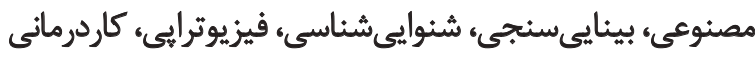
و كفتاردرماني فعاليت داشتيند. حجم نمونه يثزوهش حاضر، • 1 نفر از درمانكران داراى مدرى

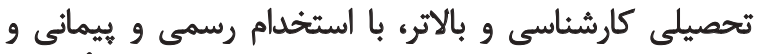

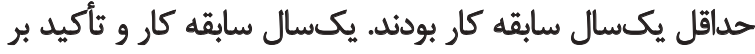

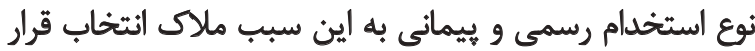

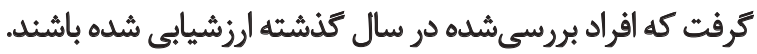

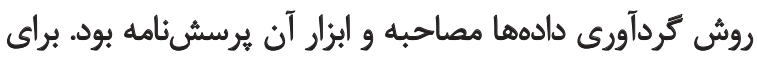

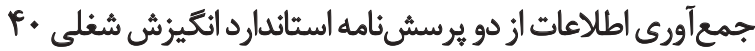
مادهاى هرزبرى و ارزيابي عملكرد كاركنان استفاده شدان

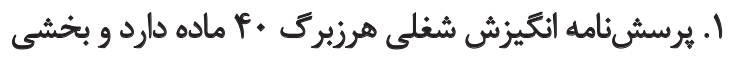

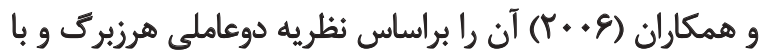

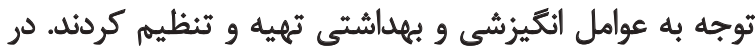

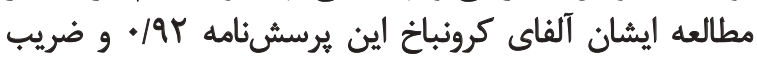

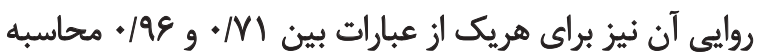

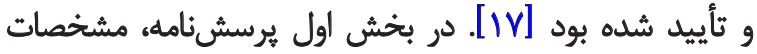

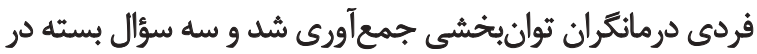

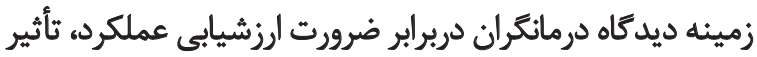

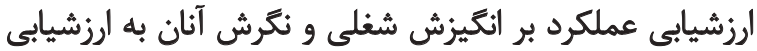

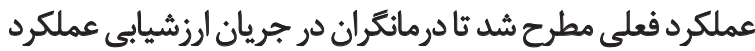
خود در يُوهش قرار بكيرند.

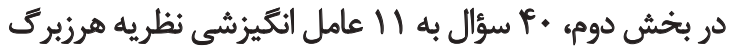

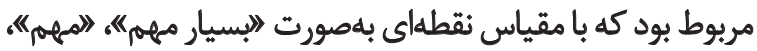

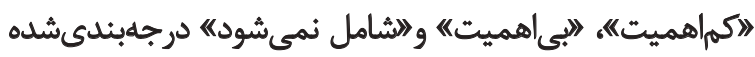

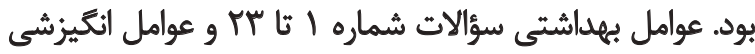

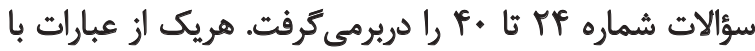

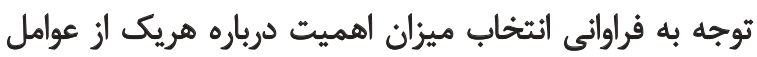

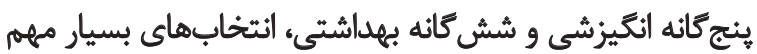

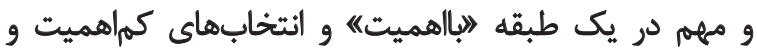

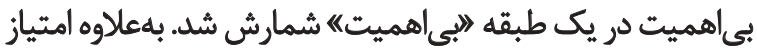

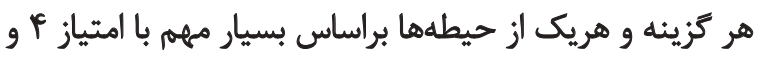

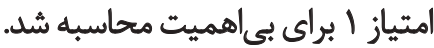

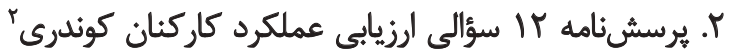

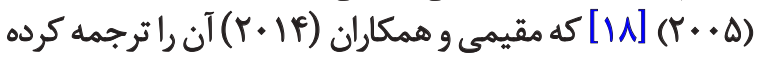

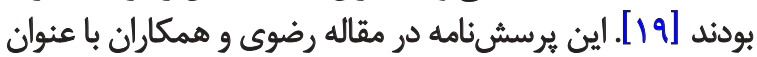

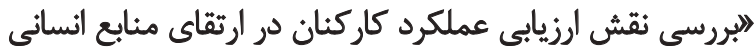

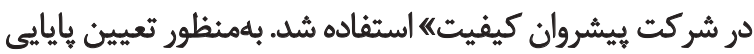

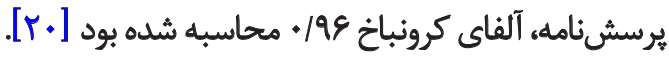

\section{Stephen}

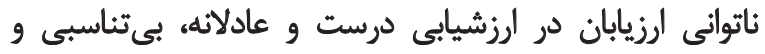

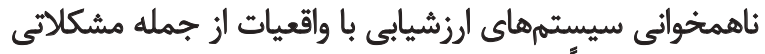

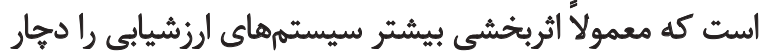

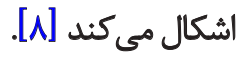

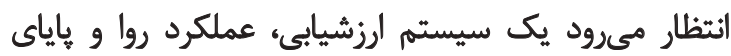

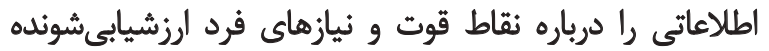

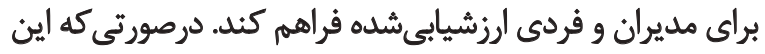

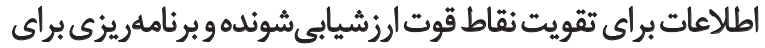

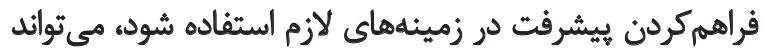

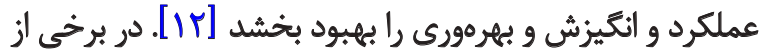

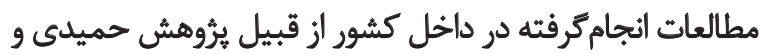

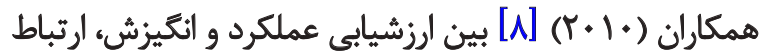

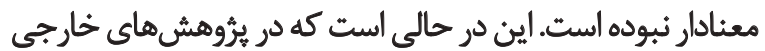

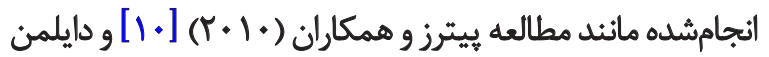

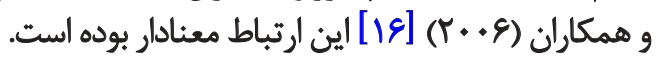

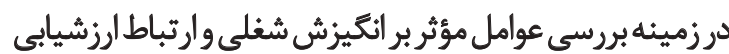

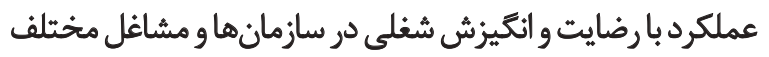

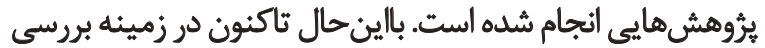

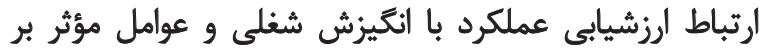

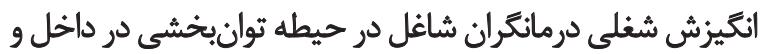
خارج از كشور يُروهشى انجام نشده است

با توجه به سختى كار درمانكران توانبخشى و ضرورت وجود

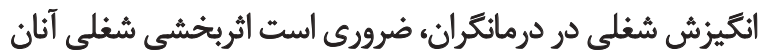

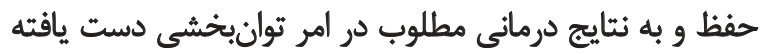

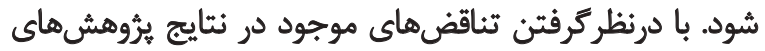

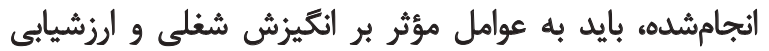

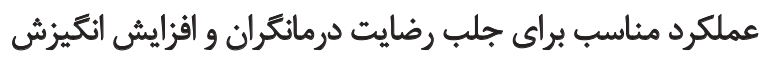

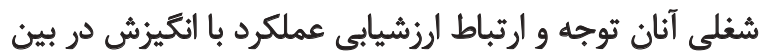

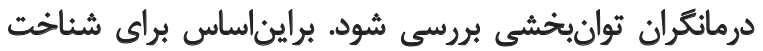

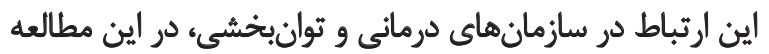

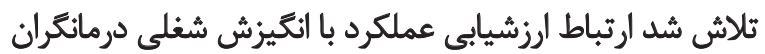

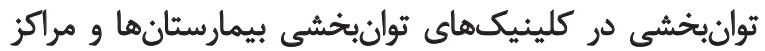

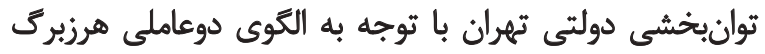

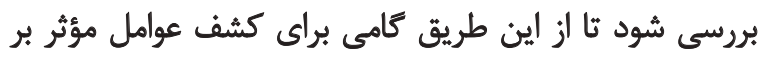

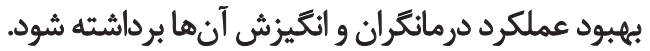

\section{روش بروشى}

اين مطالعه از نوع توصيفىتحليلى بود كه بهصورت مقطعى

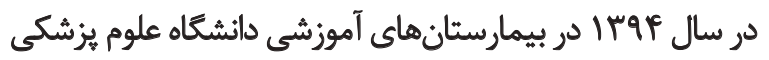

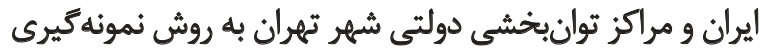

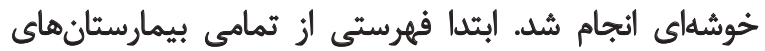

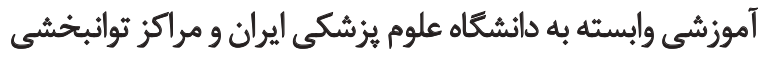
دولتى تهران تهيه و بهصورت تصادفى سه بيمارستان و جهار برار مركز 
رسمى در بيمارستان فراواتى 99/V درصد و درمانكران بيمانى

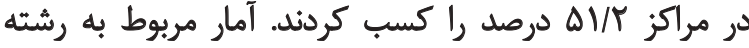

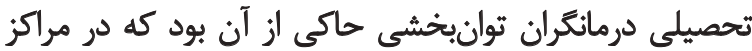

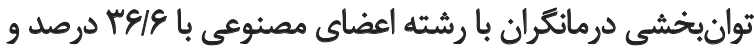

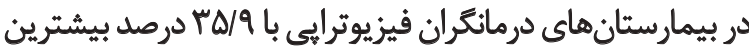

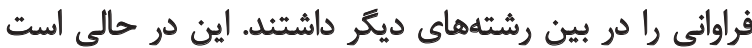

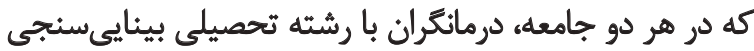

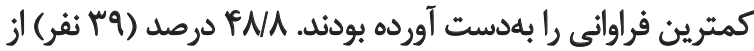

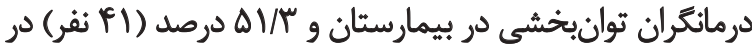
مراكز توانبخشى مشغول به كار بودند.

ميانتين امتياز ارزشيابى عملكرد درمانكَران بيمارستانى

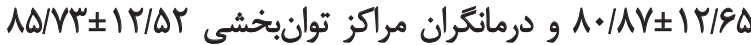

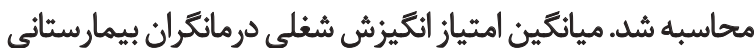
توان

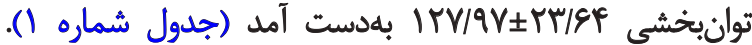

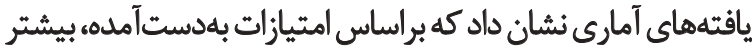

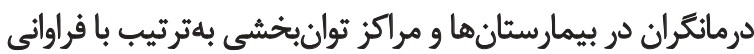

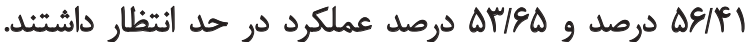

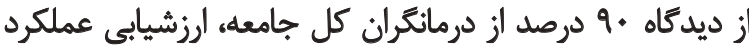

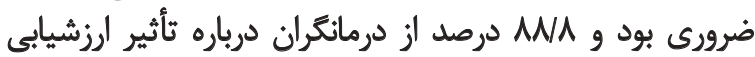

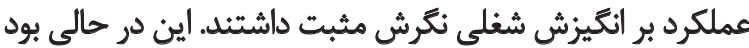

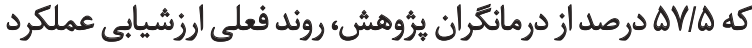

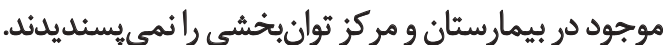

نتايج يُوهش حاضر نشان داد كه در بين درمانتران كل

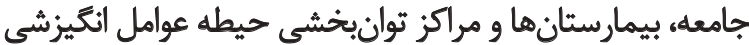

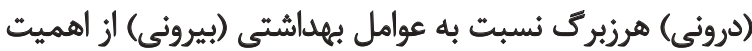

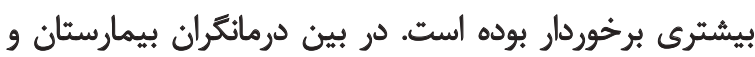

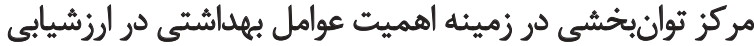

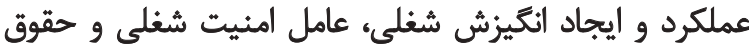

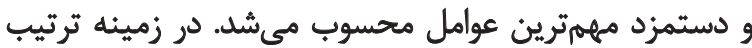

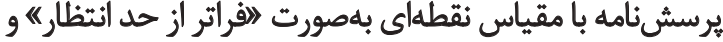

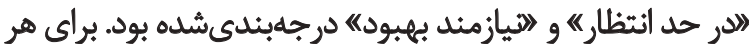

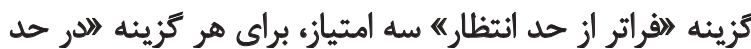

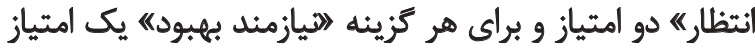

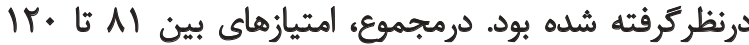

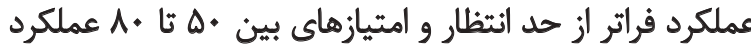

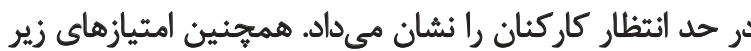

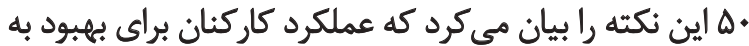

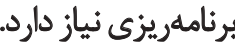

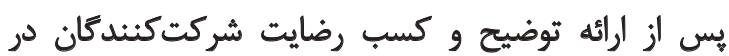

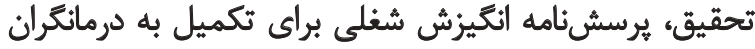

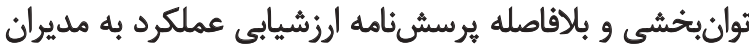

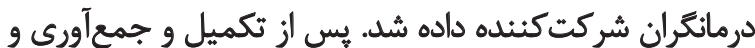

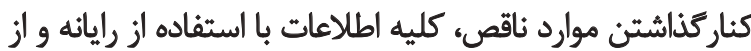

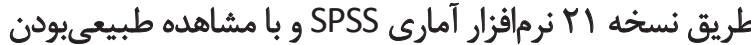

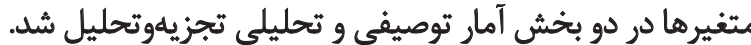

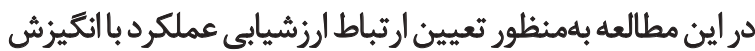

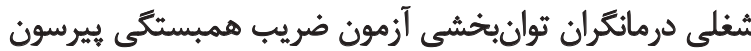

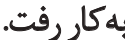

يافتهها

يافتهاى آمارى نشان داد از •1 نفرى كه در اين مطالعه

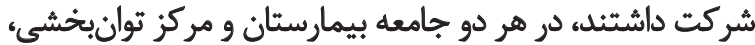

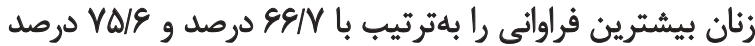

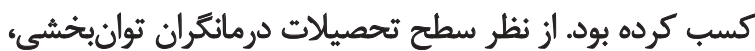

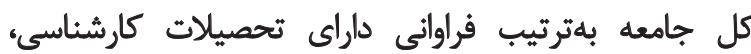

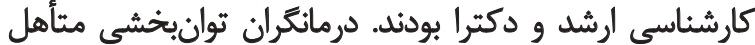

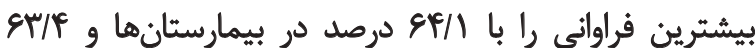

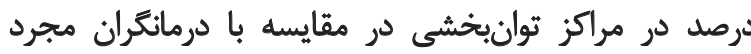

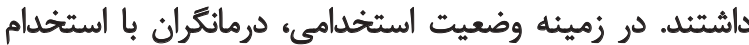

جدول ا. آمار توصيفى امتياز ارزشيابي عملكرد و انتيزش شغلى درمانتران توانبخشى به تفكيك بيمارستان و مركز توانبخشى و كل جامعه

\begin{tabular}{|c|c|c|c|c|}
\hline اتحرافمعيار & مياتكين & تعداد & أمار توصيفى & \\
\hline Ir/sa & $A \cdot / A V$ & ra & بيمارستان & \\
\hline $\mid r / \Delta r$ & $N \Delta / N$ & $p$ & مركز توانبخشى & ارزشيابى عملكرد \\
\hline$i T / M^{P}$ & S & $\Lambda$. & كل جامعه & \\
\hline ISTM & $\mid r / A S$ & rq & بيمارستان & \\
\hline$\pi / x$ & Irv/ar & $\varphi$ & هركز توانبخشى & انكيزش شغلى \\
\hline r./RA & $\mid r v / r$ & A. & كل جامعه & \\
\hline
\end{tabular}


جدول r. آمار توصيفى خردهمقياس هاى عوامل اثكيّزشى و بهداشتى نظريه هرزبرك بهتفكيك بيمارستان و مركز توانبخشى

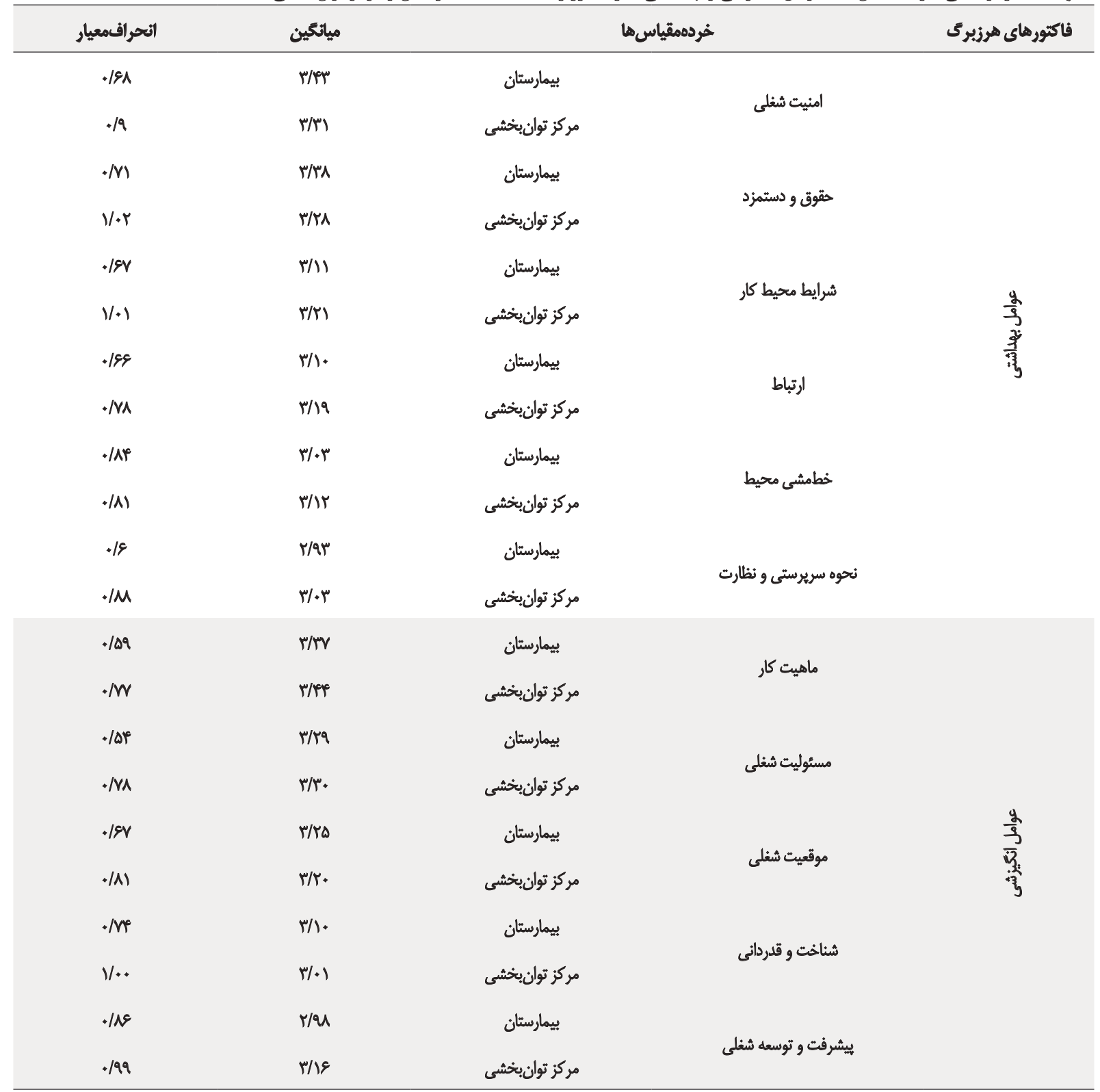

توانبخننى

بين نوع استخدام رسمى و بيمانى درمانتران توانبخشى شاغل

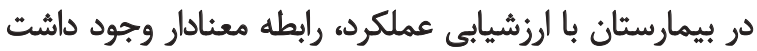

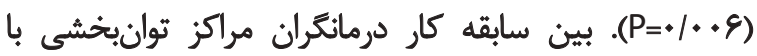

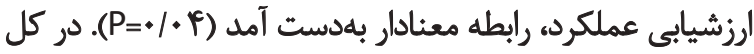

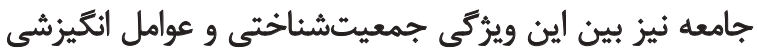

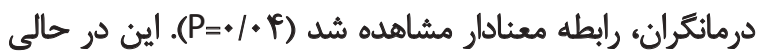

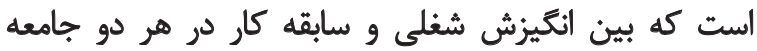

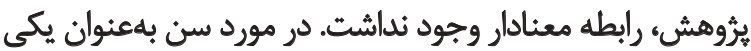

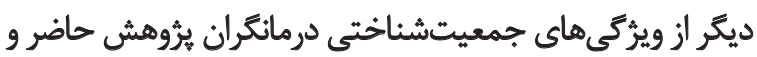

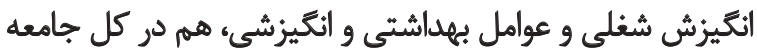

اهميت عوامل انكَيزشى در هر دو جامعه بُروهش بلهترتيب ماهيت

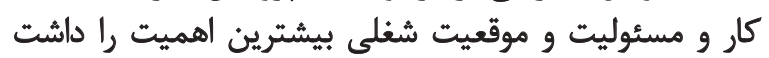
(جدول شماره ب).

همجنين براساس نتايج آمارى، در مطالعه حاضر بين ارزشيابى نئ

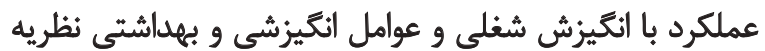

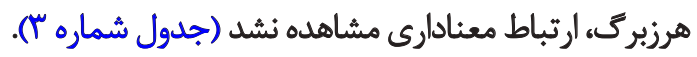
در مطالعه حاضر براساس يافتههاى حاصل از آزمونهاى آمارى

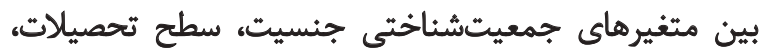

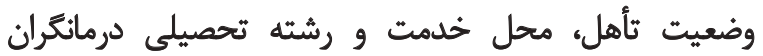
توانبشى با ارزشيابى عملكرد ارتباط معنادار وجود نداشت. 


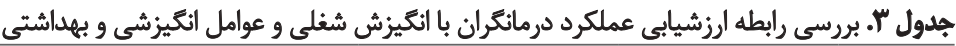

\begin{tabular}{|c|c|c|c|c|c|c|c|}
\hline \multicolumn{2}{|c|}{ عوامل بهداشتي } & \multicolumn{2}{|c|}{ عوامل اثعيزشي } & \multicolumn{2}{|c|}{ انكيزش شغلى } & & \\
\hline سطح معنادارى & ضريب همبستكى & سطح معنادارى & ضريب همبستكى & سطح معنادارى & ضريب همبستكي & & \\
\hline .119 &.$/ M$ & .1 .8 &.$/ r q$ & .111 &.$/ T \Delta$ & بيمارستان & \\
\hline.$/ M$ & -.1 .4 & $\cdot / N$ & $-1+\Delta$ & $\% 1$ &.$- \%$ & هركز توانبخشى & $y^{3}$ \\
\hline.$/ F A$ & $V / v$ &.$/ p q$ & $\% r$ &.$/ 19$ & $* / * 1$ & كل جامعه & $2^{2}$ \\
\hline
\end{tabular}

توانبخننى

جدول ع. بررسى رابطه سن درمانكران با ارزشيابى عملكرد و انكّيزش شغلى و عوامل انتّيزشى و بهبداشتى

\begin{tabular}{|c|c|c|c|c|c|c|c|c|c|}
\hline \multicolumn{2}{|c|}{ عوامل بهبداشتي } & \multicolumn{2}{|c|}{ عوامل اتكيزشي } & \multicolumn{2}{|c|}{ انغيزش شُغلى } & \multicolumn{2}{|c|}{ ارزثيابيى عملكرد } & & \\
\hline معنادطحى & ضريسئي & معثاذارى & ضمبيتئي & معثادارى & ضمبيثيّي & معثاذارى & ضمبيثئي & & \\
\hline .10 .9 &.$- / 41$ & .1 .1 & $-\rightarrow / r$ & .10 .9 & $-(|x|$ & $\% \gamma$ &.$- / 49$ & ييمارستان & \\
\hline . & $-.1 . v$ & $\cdot M r$ & -.119 &.$/ 49$ &.$- / 1 r$ & $\% A$ &.$/ T r$ & مركز توالنيخشى & 3 \\
\hline 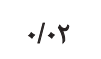 &.$- / T \Delta$ & $.1+4$ &.$- / \pi r$ & $\%$ &.$- / M \varphi$ & .108 & .1 .8 & كل جامعه & \\
\hline
\end{tabular}

توانبخننى

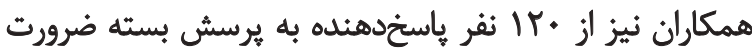

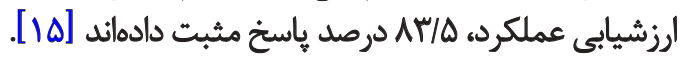

حيطه عوامل انظيزشى (درونى) هرزبرى دربرابر عوامل

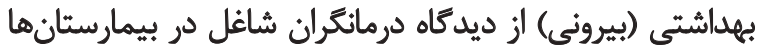

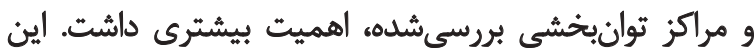

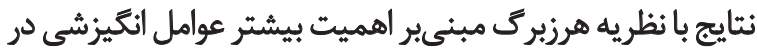

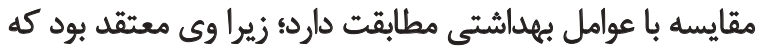

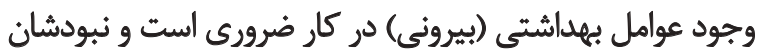

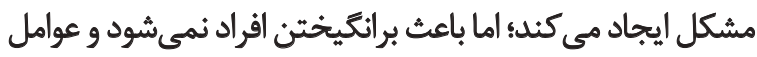

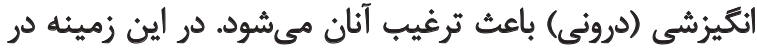

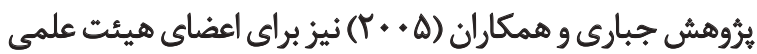

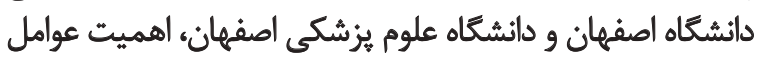

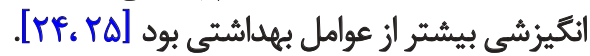
نتايج مطالعه طاهريور و همكاران (11 (Y) نيز نشان داد از

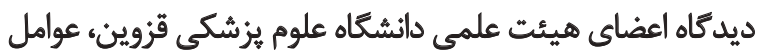

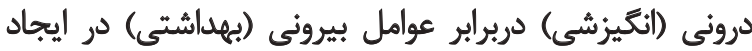

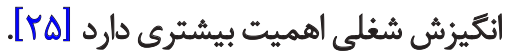

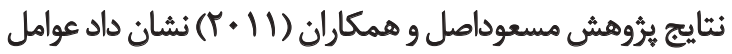

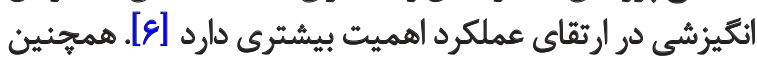

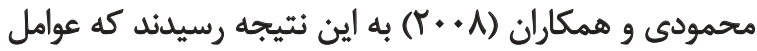

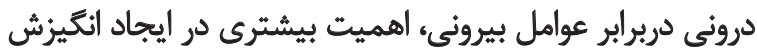

و هم در جامعه بيمارستانى، ارتباط معنادار و منفى بلدست آمد ( $(P<+1 \cdot \Delta)$

$\stackrel{4}{4}$

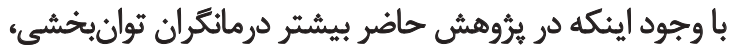

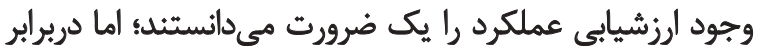

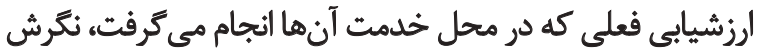

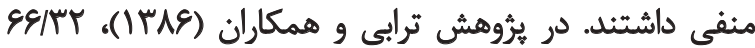

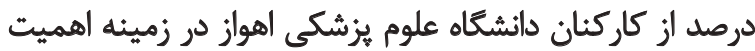

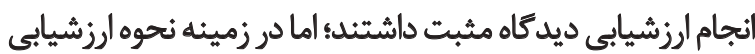

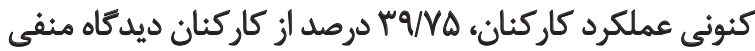

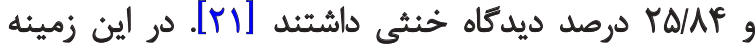

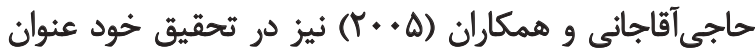

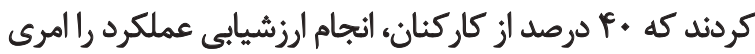

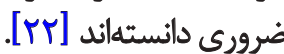

ميرسياسى در اين زمينه معتقد است كه هو درصد از كل

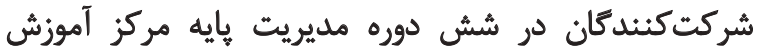

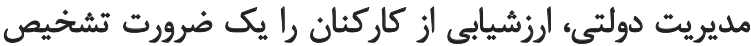

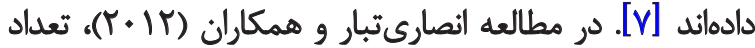

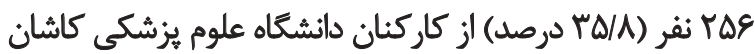

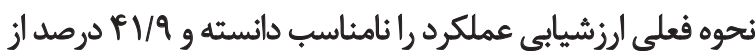

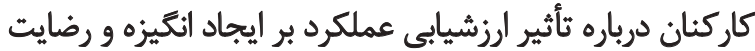

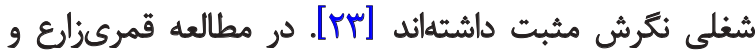




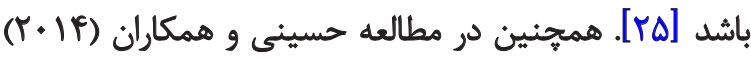

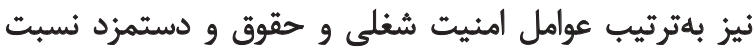

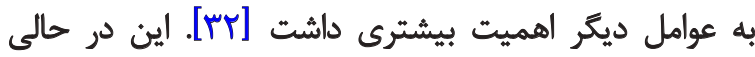

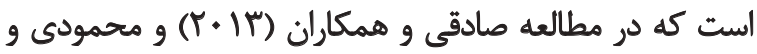

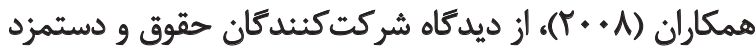

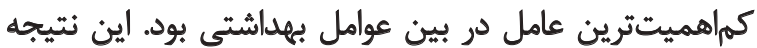

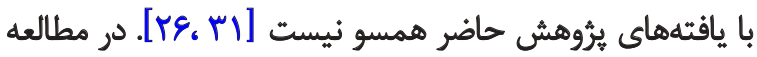

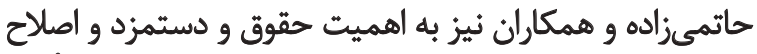
سيستم ارزيابى كاركنان براي يرداخت و حقوق مقان مناسب تأكيد

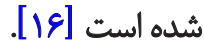

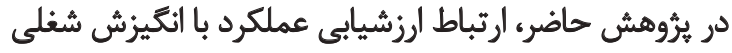

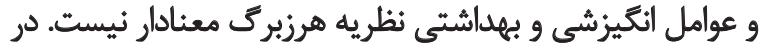

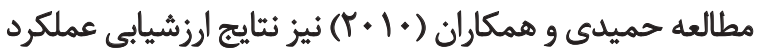

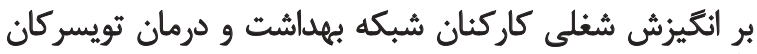

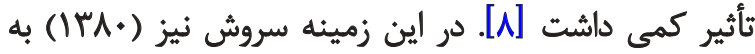

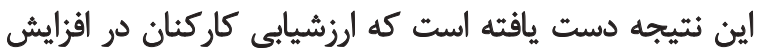

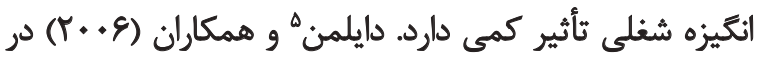

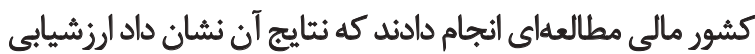

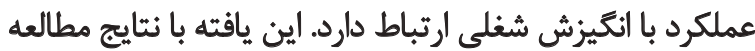

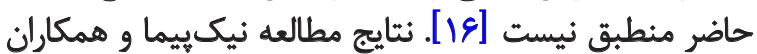
(Y. If)

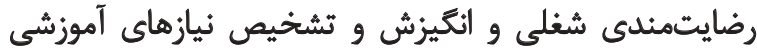

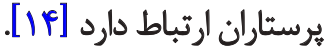

در مطالعه حاضر بين متغيرهاى جمعيتشناختى جنديت جنسيت،

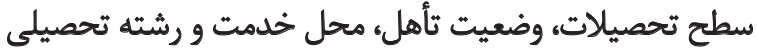

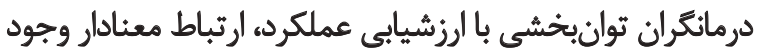

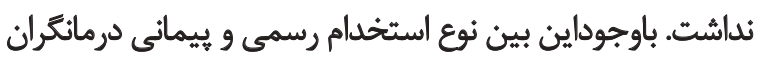

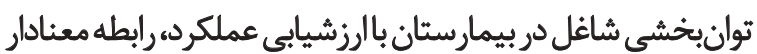

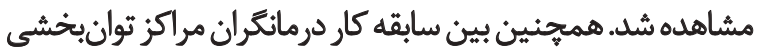

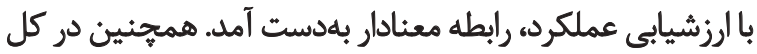

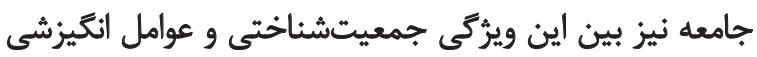

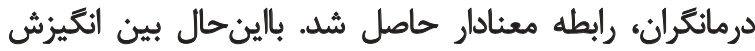

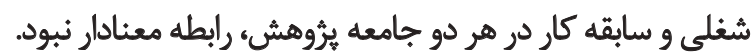

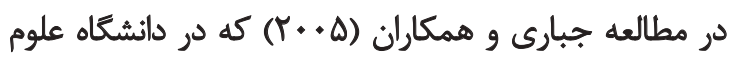

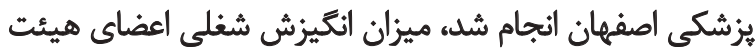

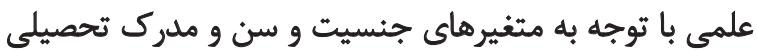

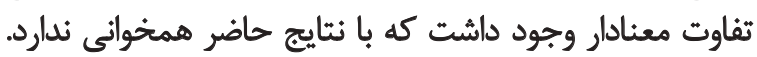

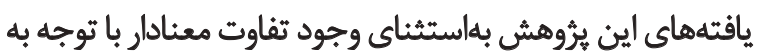

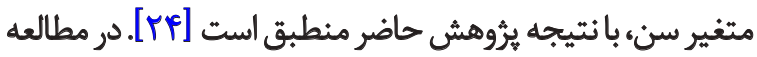

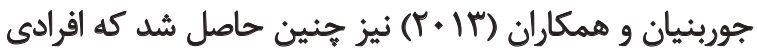

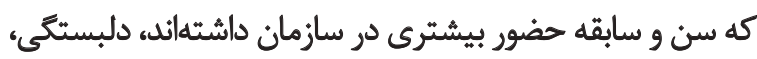

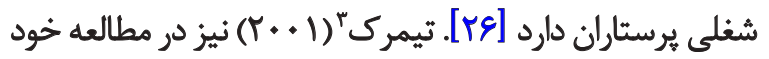

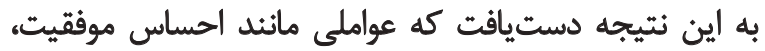

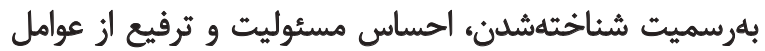

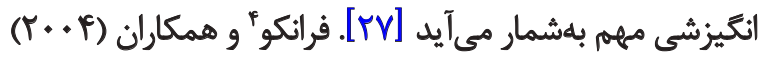

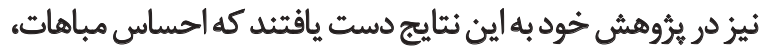

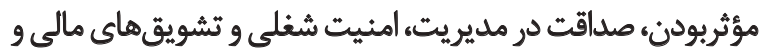

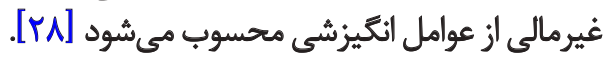

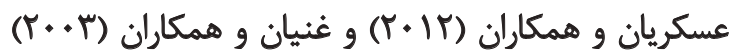

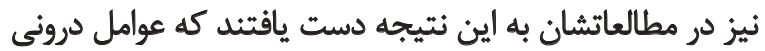

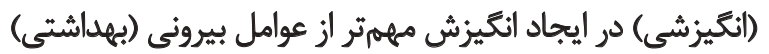

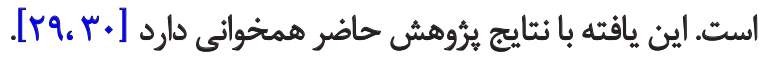

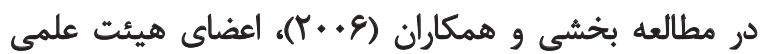

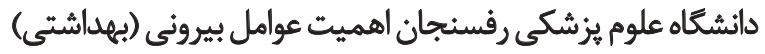

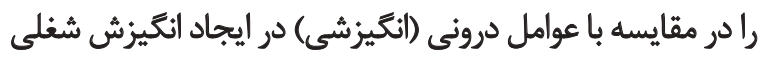

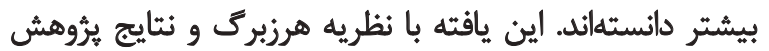

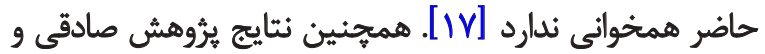

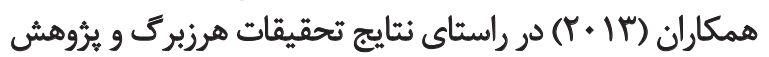

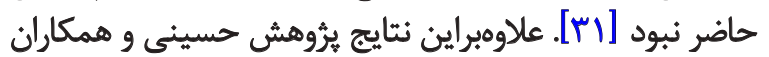

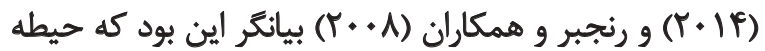

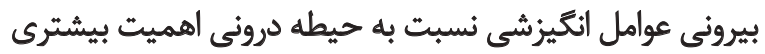

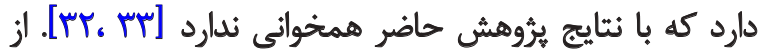

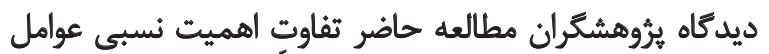

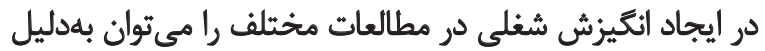

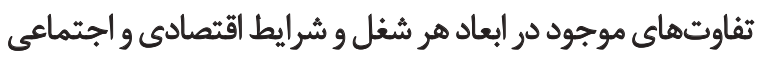

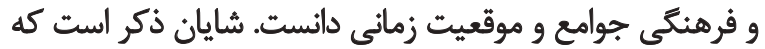
اين مسئله به بررسى جواي تكميلى نياز دارد.

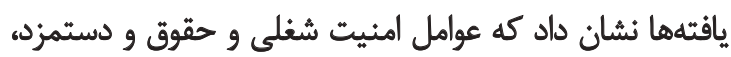

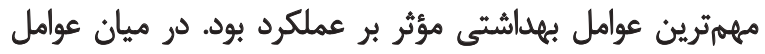

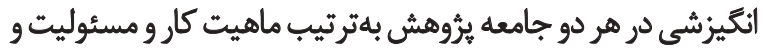

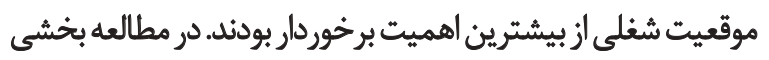

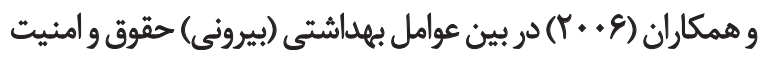

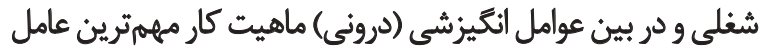

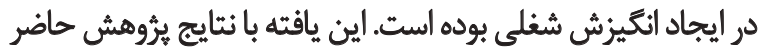

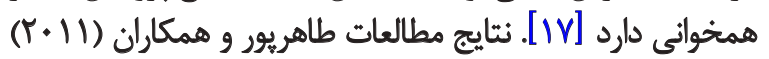

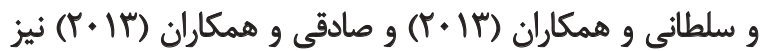

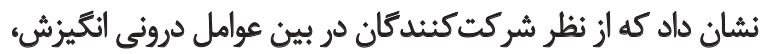

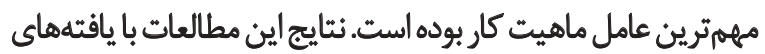

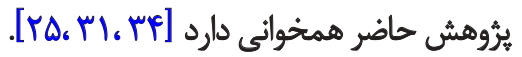
كاشانيان معتقد است كه افراد از مشاغل يُرتحرك بيشتر از

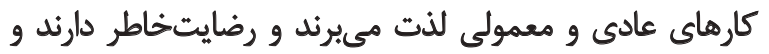

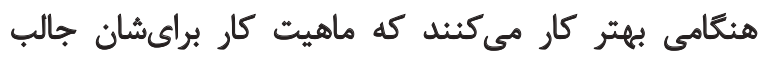


مي شود در هريك از مروههاي توانبخشى، متناسب با نيازها و

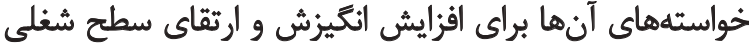

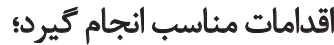

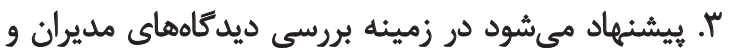

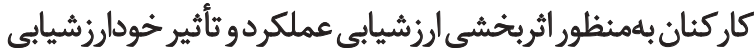

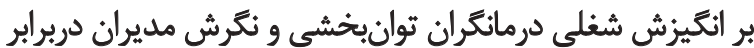

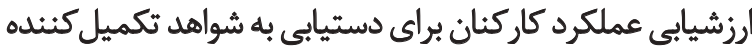
نتايج ئروهش حاضر، تحقيقاتى انجام يذيرد.

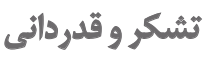

اين مقاله از هايان نامه مقطع كارشناسى ارشد خانم الهيه

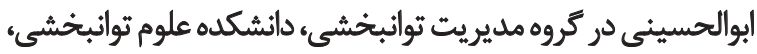

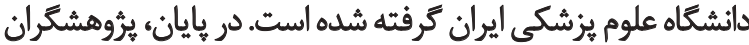

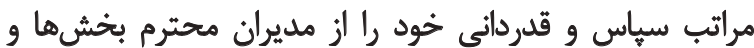

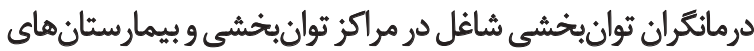

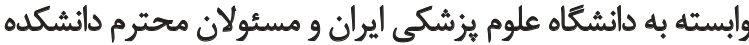

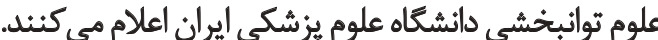

رضايت و تعهلد بيشترى نسبت به سازمان دارند [عب].

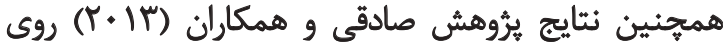

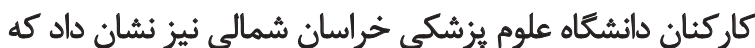

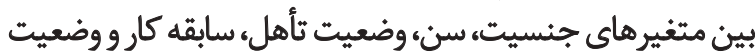

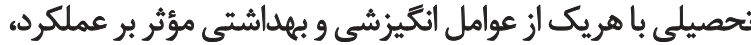

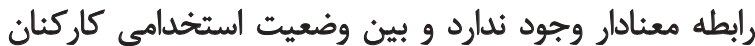

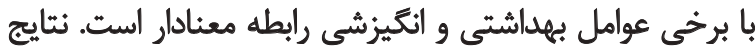

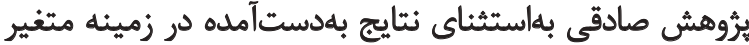

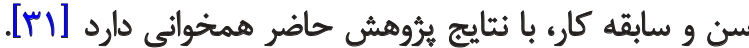

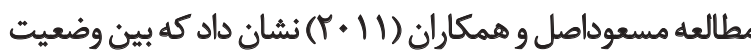

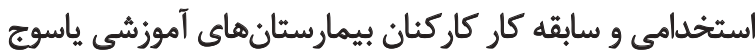

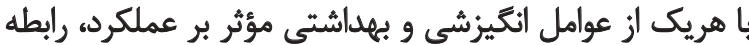

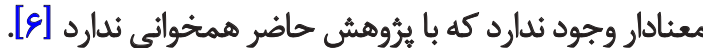

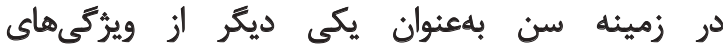

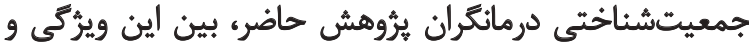

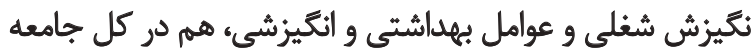

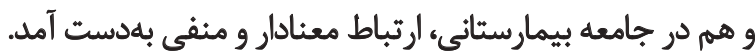

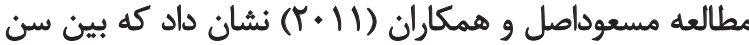

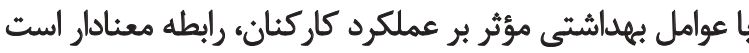

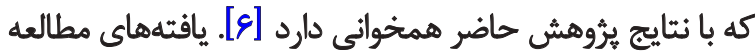

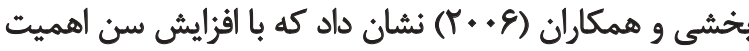

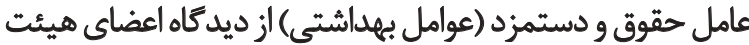
علمى افزايش يافته است [IV]

\section{نتيجهيكيرى}

نتايج اين مطالعه، مديران و مسئولان امر رابه تأكيد در شناسايى

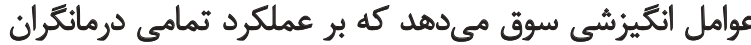

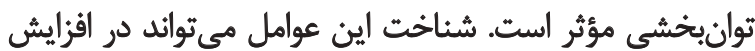

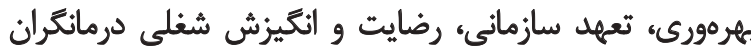

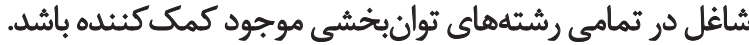
از محدوديتهاى اين مطالعه مي توان به كمبود برُوهشهاى

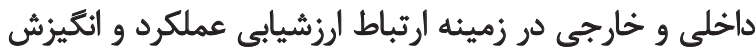

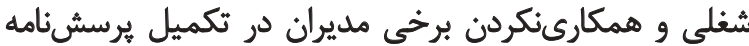
مربوط به ارزشيابى عملكرد درمانكران اشاره كردان دردي

براساس نتايج يُوهش حاضر، ييشنهادهاى زير ارائه مىشود: ا. مسئولان امر با درنظركرفتن سختى كار درمانكران

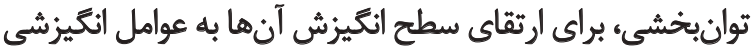

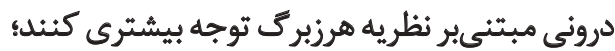

ب. با توجه به اينكه عوامل ماهيت كار، مسئوليت و امنيت

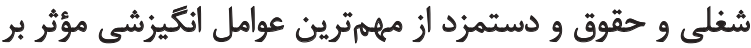

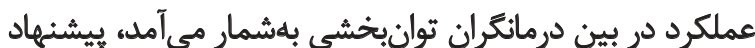




\section{References}

[1] Hamuzadeh P, Sadeghi Jamil, Moradkhani Baryar. [Effective factors on job motivation in managers of teaching hospitals of the Orumieh University of Medical Sciences from view point of them in 2009 (Persian)]. Journal of Urmia Nursing and Midwifery Faculty. 2011; 9(1):15-22.

[2] Baradaran Kazemzadeh R, Hashemi M. [A study of job motivation factors in the organization based on the Herzberg theory and proposing two measurement models for motivation and hygiene factors: a case study of the oil and energy industrial development company (Persian)]. Sharif Journal of Industrial Engineering and Management. 2010; 25(49):25-37.

[3] Mohammadi-Shahbolaghi F. [Theoretical foundations of nursing rehabilitation (Persian)]. Tehran: University of Social Welfare and Rehabilitation Sciences; 2007.

[4] Rezaei A, Hoseini M, Mehrdad N. [The influential factors in profiting the research evidences and results in clinical practice by rehabilitation practitioners (Persian)]. Archives of Rehabilitation. 2012; 13(3):50-60.

[5] Karimi-Dermani H. [Rehabilitation of specific groups with an emphasis on social services (Persian)]. $1^{\text {st }}$ ed. Tehran: Roshd; 2011.

[6] Masoud Asl I, Akhavan Behbahani A, Nosratinejad F, Gholamrezanejad A. [The relationship between job satisfaction and Hertzberg's motivative-hygienic factors in staffs of Yasouj Hospitals (Persian)]. Quarterly Medical Journal of Islamic Azad Univesity. 2011; $20(1): 52-57$.

[7] Mirsepasi N. [Human recourse management and work relation (Persian)].18 ${ }^{\text {th }}$ ed. Tehran: Mir; 2001.

[8] Hamidi Y, Najafi L, Vatankhah S, Afkar A. [The effect of performance appraisal results on the personnels motivation and job promotion (Persian)]. Journal of Health System. 2010; 1(1):41-48.

[9] Jabari A, Hoseini M, Fatourechi S, Hoseini A, Farzi M. [Designing a valid and reliable tool for assessing the occupational therapists clinical competency (Persian)]. Archives of Rehabilitation. 2014;14(4):44-49.

[10] Peters DCS, Mahapatra P, Steinhardt L. Job satisfaction and motivation of health workers in public and private sectors: Crosssectional analysis from two Indian states. Human Resources for Health. 2010; 8(1). doi: 10.1186/1478-4491-8-27

[11] Jorbonian A, Makarem A, Hoseini M, Bakhshi E. [The relationship between organizational citizenship behavior and organizational commitment in welfare staff in Tehran 2013 (Persian)]. Archives of Rehabilitation. 2015; 16(1):18-25.

[12] Taghavi Larijani T, Yekya Parsa Z, Kazemnejad A, Mazaheri A. [Outcomes of the performance appraisal and its relation with nurses job motivation (Persian)]. Journal of Nursing Practice Today. 2007; 4(12):39-45.

[13] Pazargadi M, Khatiban M, Ashktorab T. [Performance evaluation of nursing faculty members: a qualitative study (Persian)]. Iranian Journal of Medical Education. 2008; 8(2):213-226.

[14] Nikpeyma N, Abed-Saeedi Z, Azargashb Z, Alavi-Majd H. [A review of nurses performance appraisal in Iran. Health Promotion Management (Persian)]. Journal of Health Promotion Management. 2014; 3(1):74-83.
[15] Ghamari-Zare Z, Purfarzad Z, Anoosheh M, Seraji A, Ghorbani M. [The correlation between quality of performance appraisal and job satisfaction of nurses (Persian)]. Quarterly Journal of Nursing Management. 2013; 1(3):18-27.

[16] Hatamizade N, Tavafi N, Kazemzade A, Jazayeri A. [Organizational stressors and related stress intensities in Tehran's comprehensive rehabilitation centers: From the employees' point of view (Persian)]. Archives of Rehabilitation. 2006; 7(4):30-35.

[17] Bakhshi Aliabadi H, Norouzi D, Hosseini Z. [Effective factors on job motivation in academic members of Rafsanjan Medical University (Persian)]. Journal of Medical Education. 2006; 4(12):33-41.

[18] Stephen E, Condrey. Handbook of Human Resource Management in Government. $2^{\text {nd }}$ edition. 2005.

[19] Moghimi M, Ramezan M. [Emplyees performance evaluation (Persian)]. Journal of Management. Tehran: Rahdan; 2014

[20] Razavi H, Emamgholi S, Ansari Amoli P. [Examines the role of human resources in improving employee performance evaluation study leading quality (Persian)]. Paper presented at: The $6^{\text {th }}$ International Conference on Management, Finance and Entrepreneurship; 2015 October 17-18; Istanbul, Turkey.

[21] Torabipoor A, Sotoudeh S. [Employees attitude about annual performance evaluation of faculties affiliated to Ahvaz University of Medical Sciences (Persian)]. Journal of Health Administration. 2010; 12(38):17-22.

[22] Haji-Aghajani S. [Study on attitude in personnel of Semnan University of Medical Sciences about annual performance evaluation (Persian)]. Quarterly Journal of Teb va Tazkiey. 2005; 14(3):37-43.

[23] Ansari-Tabar A, Charkhchi A, Sarafraz Z. [Attitude of staff of Kashan University of Medical Sciences about how to evaluate annual performance (Persian)]. Journal of Homaye Salamat. 2011; 8(4):11-17.

[24] Jabari F, Rajaiepour S, Jafari E. [A comparative study of Esfahan University and Esfahan University of Medical Sciences faculty member's job motivation based on Herzberg`s Theory (Persian)]. Journal of Health Information Management. 2005; 1(1):15-20.

[25] Taherpour M, Sefidi F, Javadi A. [Identifying job motivation from Qazvin University of Medical Sciences faculty members viewpoints (Persian)]. Research in Medical Education. 2011; 2(2):33-39.

[26] Mahmoudi H, Ebrahimiyan A, Soleymani M, Ebadi A, Hafezi S, Feyzi F, Sadeghi M. Job Motivation Factors of nurses critical care (Persian)]. Journal of Behavioral Sciences. 2008; 1(2):171-8.

[27] Timmreck TC. Managing motivation and developing job satisfaction in the health care worker environment Health Care Management. 2001; 20(1):42-58. PMID: 11556553

[28] Franco LM BS, Kanfer R, Stubblebine P. Determinants and consequences of health worker motivation in hospitals in Jordan and Georgi. Social Science \& Medicine. 2004; 58(2):343-55. doi: 10.1016/s0277-9536(03)00203-x

[29] Askarian M, Bagheri SH. [Study on job motivation of academic board members of NAJA training Deputy according to twofactor Herzberg Theory (Persian)]. Police Management Studies Quarterly. 2012; 7(1):7-39. 
[30] Ghanyan M. [Structures affecting job satisfaction agricultural promoters Azarbaijan Qarbi, Kurdestan and Kermanshah province (Persian)]. Scientific Journal of Agriculture. 2003; 26(1):93103.

[31] Sadeghi A, Darzi-Ramandi S, Toroski M, Emami O, Heydari Gh, Shahraki H. [Viewpoints of North Khorasan University of Medical Sciences about the motivation and hygiene factors affecting their performance and satisfaction (Persian)]. Sadra Medical Sciences Journal. 2014; 2(2):111-22.

[32] Hoseyni N, Mirzaei M, Faryabi R, Mokhtari-Ardekan A, ShakerArdekani M, Mirzaei M. [Effective factors in job motivation of faculty members in Shahid Sadoughi University of Medical Sciences: an application of Herzberg Motivation Theory (Persian)]. Iranian Journal of Medical Education. 2014; 13(12).1040-50.

[33] Ranjbar M, Vahidshahi K. [Effective factors on faculty members job satisfaction in Mazandaran University of Medical Sciences, School of Medicine, 2006 (Persian)]. Strides in Development of Medical Education. 2008; 4(2):92-99.

[34] Soltani H, Parsa M, Rashidi M. [Performance evaluation system and incentive-cultural factors influencing employee performance: a case study (Persian)]. Quarterly Journal of Productivity Management. 2013; 7(26):147-73.

[35] Dieleman M, Toonen J, Toure H, Martineau T. The match between motivation and performance management of health sector workers in Mali. Human Resources for Health. 2006; 9(4):2-9. doi: 10.1186/1478-4491-4-2

[36] Makarem A, Jorbonyan A, Hosseini M A, Bakhshi E. [The Relationship between organizational citizenship behavior and organizational commitment in welfare staff (Tehran 2013) (Persian)]. Archives of Rehabilitation. 2015; 16(1):18-25. 
